\title{
Diagnosis and management of xerostomia and hyposalivation
}

This article was published in the following Dove Press journal:

Therapeutics and Clinical Risk Management

22 December 2014

Number of times this article has been viewed

\author{
Alessandro Villa ${ }^{1,2}$ \\ Christopher L Connell ${ }^{3}$ \\ Silvio Abati $^{4}$ \\ 'Division of Oral Medicine and \\ Dentistry, Brigham and Women's \\ Hospital, Boston, MA, USA; \\ ${ }^{2}$ Department of Oral Medicine, \\ Infection and Immunity, Harvard \\ School of Dental Medicine, Boston, \\ MA, USA; ${ }^{3}$ Department of General \\ Dentistry, Boston University Henry M \\ Goldman School of Dental Medicine, \\ Boston, MA, USA; ${ }^{4}$ Dental Clinic, \\ Department of Health Sciences, \\ University of Milan, Milano, Italy
}

\begin{abstract}
Xerostomia, the subjective complaint of dry mouth, and hyposalivation remain a significant burden for many individuals. Diagnosis of xerostomia and salivary gland hypofunction is dependent upon a careful and detailed history and thorough oral examination. There exist many options for treatment and symptom management: salivary stimulants, topical agents, saliva substitutes, and systemic sialogogues. The aim of this review is to investigate the current state of knowledge on management and treatment of patients affected by xerostomia and/or hyposalivation.
\end{abstract}

Keyword: saliva stimulation, dry mouth, saliva substitutes, sialogogues

\section{Introduction}

Xerostomia is defined as the subjective complaint of dry mouth. ${ }^{1}$ Interestingly, patients complaining of xerostomia frequently do not show any objective sign of hyposalivation and their symptoms may be secondary to qualitative and/or quantitative changes in the composition of saliva. ${ }^{2,3}$ The normal stimulated salivary flow rate averages $1.5-2.0 \mathrm{~mL} / \mathrm{min}$ while the unstimulated salivary flow rate is approximately $0.3-0.4 \mathrm{~mL} / \mathrm{min} ., 5$ A diagnosis of hyposalivation is made when the stimulated salivary flow rate is $\leq 0.5-0.7 \mathrm{~mL} / \mathrm{min}$ and the unstimulated salivary flow rate is $\leq 0.1 \mathrm{~mL} / \mathrm{min} .^{5-7}$ Xerostomia in patients with objective hyposalivation is diagnosed when the rate of saliva flow is less than the rate of fluid absorption across the oral mucosa plus the rate of fluid evaporation from the mouth. ${ }^{8}$

Chronic xerostomia remains a significant burden for many individuals. In particular, it may affect speech, chewing, swallowing, denture-wearing, and general well-being. ${ }^{9}$ Xerostomia secondary to hyposalivation may also result in rampant dental caries, oral fungal infections (eg, candidiasis), taste changes, halitosis, or burning mouth., ${ }^{5,10,11}$ The most frequent cause of hyposalivation is the use of certain medications (such as anticoagulants, antidepressants, antihypertensives, antiretrovirals, hypoglycemics, levothyroxine, multivitamins and supplements, non-steroidal anti-inflammatory drugs, and steroid inhalers) (Villa et al, unpublished data, 2014), followed by radiotherapy to the head and neck, and Sjögren's syndrome. ${ }^{12}$ Other factors include depression, anxiety and stress, or malnutrition. ${ }^{13}$

The prevalence of xerostomia in the population ranges from $5.5 \%$ to $46 \%$. Studies have shown differences in the prevalence between the sexes and xerostomia appears to increase with increasing age. A possible explanation is that older individuals take several xerogenic drugs for their chronic conditions and this may lead to an overall reduction of the unstimulated salivary flow rate..$^{1,10,12,14-18}$ Xerostomia remains an unresolved common complaint especially among the geriatric population, despite seeking medical or dental consultation. ${ }^{19}$ The aim of this review is to explore the current state 
of knowledge on management and treatment of patients affected by xerostomia and hyposalivation.

\section{Diagnosis of xerostomia and salivary gland hypofunction}

The diagnosis of xerostomia and salivary gland hypofunction requires a thorough medical history. Particular attention should be given to the reported symptoms, medication use, and past medical history.

Patients with salivary gland hypofunction typically complain of dry mouth, difficulty swallowing and/or speaking; they hardly tolerate spicy, acidic, and crunchy food and often times report taste changes or difficulty wearing dentures. ${ }^{20}$

Several questionnaires have been proposed to identify patients with xerostomia and hyposalivation. Fox et al developed a questionnaire on the severity of dry mouth, which may predict true hyposalivation (Table 1). ${ }^{21}$ A positive answer to all the questions was associated with low saliva flow rates. A few years later, Thomson et al created an eleven-item summated rating scale on the severity of chronic xerostomia (Xerostomia Inventory). ${ }^{22}$ Each response was scored and summed to give a final score. van der Putten et al shortened the Xerostomia Inventory and proposed the Summated Xerostomia Inventory-Dutch. Only five items were included. ${ }^{2}$ In the questionnaire developed by Sreebny and Valdini, the question "does your mouth usually feel dry" was found to have had a sensitivity of $93 \%$, a specificity of $68 \%$, a negative predictive value of $98 \%$, and a positive predictive value of $54 \%$ for hyposalivation. ${ }^{23}$ Eisbruch et al studied the grade of xerostomia through a validated scale made of three

Table I Questionnaires to assess dry mouth

\begin{tabular}{|c|c|c|}
\hline Authors & Questions/statements & Response/scoring \\
\hline Fox et $\mathrm{al}^{21}$ & $\begin{array}{l}\text { I) Does the amount of saliva in your mouth seem to } \\
\text { be too little, too much, or you do not notice it? } \\
\text { 2) Do you have any difficulty swallowing? } \\
\text { 3) Does your mouth feel dry when eating a meal? } \\
\text { 4) Do you sip liquids to aid in swallowing dry food? }\end{array}$ & Yes/no \\
\hline Thomson et $\mathrm{al}^{22}$ & $\begin{array}{l}\text { I) My mouth feels dry } \\
\text { 2) I have difficulty in eating dry foods } \\
\text { 3) I get up at night to drink } \\
\text { 4) My mouth feels dry when eating a meal } \\
\text { 5) I sip liquids to aid in swallowing food } \\
\text { 6) I suck sweets or cough lollies to relieve dry mouth } \\
\text { 7) I have difficulties swallowing certain foods } \\
\text { 8) The skin of my face feels dry } \\
\text { 9) My eyes feel dry } \\
\text { 10) My lips feel dry } \\
\text { II) The inside of my nose feels dry }\end{array}$ & $\begin{array}{l}\text { Never = scoring I } \\
\text { Hardly ever = scoring } 2 \\
\text { Occasionally = scoring } 3 \\
\text { Fairly often = scoring } 4 \\
\text { Very often = scoring } 5\end{array}$ \\
\hline van der Putten et $\mathrm{al}^{2}$ & $\begin{array}{l}\text { I) My mouth feels dry when eating a meal } \\
\text { 2) My mouth feels dry } \\
\text { 3) I have difficulty in eating dry foods } \\
\text { 4) I have difficulties swallowing certain foods } \\
\text { 5) My lips feel dry }\end{array}$ & $\begin{array}{l}\text { Never }=\text { scoring } 1 \\
\text { Occasionally }=\text { scoring } 2 \\
\text { Ever }=\text { scoring } 3\end{array}$ \\
\hline Eisbruch et $\mathrm{al}^{24}$ & $\begin{array}{l}\text { Subjective grade I= no disability } \\
\text { Subjective grade } 2=\text { dryness requiring additional fluids } \\
\text { for swallowing } \\
\text { Subjective grade } 3=\text { dryness causing dietary alterations } \\
\text { or interference with sleep, speaking, or other } \\
\text { activities }\end{array}$ & Not applicable \\
\hline Pai et $\mathrm{al}^{25}$ & $\begin{array}{l}\text { I) Rate the difficulty you experience in speaking due } \\
\text { to dryness } \\
\text { 2) Rate the difficulty you experience in swallowing } \\
\text { due to dryness } \\
\text { 3) Rate how much saliva is in your mouth } \\
\text { 4) Rate the dryness in your mouth } \\
\text { 5) Rate the dryness in your throat } \\
\text { 6) Rate the dryness of your lips } \\
\text { 7) Rate the dryness of your tongue } \\
\text { 8) Rate the level of your thirst }\end{array}$ & $100 \mathrm{~mm}$ horizontal scale \\
\hline
\end{tabular}


grades (Table 1). ${ }^{24}$ Finally, Pai et al proposed an eight-item visual analogue scale with which patients were asked to score their xerostomia. ${ }^{25}$

One of the major risk factors for xerostomia and hyposalivation is the use of certain medications. In addition, polypharmacy has been shown to significantly influence patients' saliva flow. 10,26 "Xerogenic" medications associated with a low unstimulated saliva flow are: psycholeptics, psychoanaleptics (particularly selective serotonin reuptake inhibitors), oral antidiabetics (mainly sulfonylureas), respiratory agents, quinine, antihypertensive agents (such as thiazides and calcium channel blockers), urinary antispasmodics, glucosamine, non-steroidal anti-inflammatory drugs, opioids, ophthalmologicals, and magnesium hydroxide. ${ }^{7,27}$ Clinicians should review the drug history carefully in order to identify medications that can reduce the saliva flow in patients complaining of xerostomia. Finally, a thorough medical history should be obtained in order to identify other known causes of xerostomia such as Sjögren's syndrome, radiation treatment of the head and neck region, and other systemic diseases (particularly hypertension, asthma, diabetes mellitus, hematological diseases, thyroid diseases, rheumatic diseases, psychiatric diseases, and eating disorders).

A careful oral examination is fundamental to identify clinical signs pathognomonic for hyposalivation. Several helpful signs have been proposed by Osailan et al: 1) sticking of an intraoral mirror to the buccal mucosa or tongue; 2) frothy saliva; 3) no saliva pooling in floor of mouth; 4) loss of papillae of the tongue dorsum; 5) altered/smooth gingival architecture; 6) glassy appearance to the oral mucosa (especially the palate); 7) lobulated/deeply fissured tongue; 8) cervical caries (more than two teeth); and/or 9) mucosal debris on palate (except under dentures). ${ }^{28}$

\section{Measurement of salivary flow rates}

Most of the methods to measure the salivary flow are easy to perform and require little time. Salivary flow rates are usually measured for at least 5 minutes after an overnight fast or 2 hours after a meal. ${ }^{29}$ Unstimulated whole salivary flow rate is assessed with the patient seated in an upright position. Patients are asked to constantly drain saliva from the lower lip into a graduated container for 15 minutes (draining method).$^{30}$ Leal et al proposed to collect saliva with preweighed cotton rolls placed at the orifices of the ducts of the major salivary glands and then reweigh them after the collection time. ${ }^{14}$ The saliva can also be collected using a graduated absorbent strip placed on the floor of the mouth (readings at 1,2 , and 3 minutes). ${ }^{31}$ Other methods to assess the unstimulated whole salivary flow rate include the spitting method and the suction method. ${ }^{14,30}$ Stimulated salivary flow rate is measured after the patient has chewed an unflavored gum base or paraffin wax (1-2 g) for 1 minute..$^{32}$ Otherwise, saliva production can be stimulated with a solution of $2 \%$ citric acid placed on the sides of the tongue at intervals of 30 seconds. The saliva is then collected into a graduated cylinder for 5 minutes. Salivary flow (both stimulated and unstimulated) can also be measured selectively from one major salivary gland or minor salivary gland. The parotid gland secretion is typically collected by using a suction device and placing a cup (the Lashley or Carlson-Crittenden cup) over the Stensen duct. ${ }^{33}$ The submandibular gland salivary flow rate can be measured by incannulation of the Wharton's duct. ${ }^{34}$ A similar system to measure the salivary flow rates for both the sublingual and submandibular glands has been developed by Wolff et al. ${ }^{35}$ Minor salivary gland salivary flow can be measured with micropipette and absorbent filter paper (the Periotron ${ }^{\circledR}$ method; ProFlow ${ }^{\mathrm{TM}}$ Inc, Amityville, NY, USA). ${ }^{36}$ Flow rates can be calculated in units of $\mu \mathrm{L} / \mathrm{min} / \mathrm{cm}^{2}$ of mucosal area. ${ }^{37}$

\section{Management and treatment of xerostomia}

Several treatment strategies for the management of xerostomia have been proposed in the past years and they all aim to reduce patients' symptoms and/or increase salivary flow. Easy remedies are proper hydration; increase in humidity at night-time; avoidance of irritating dentifrices and crunchy/hard foods; and use of sugar-free chewing gums/candy. ${ }^{38}$ Medications include mucosal lubricants, saliva substitutes, and saliva stimulants.

\section{Systemic sialogogues}

Pilocarpine and cevimeline are two systemic US Food and Drug Administration-approved sialogogues for treatment of dry mouth. Their effect depends on the presence of functional glandular tissue. Oral pilocarpine is a parasympathomimetic medication with muscarinic action. ${ }^{39,40}$ Cevimeline is a salivary gland stimulant with a stronger affinity for M3 muscarinic receptors. ${ }^{41-44}$ Pilocarpine and cevimeline provide a similar benefit in patients with dry mouth. ${ }^{45}$ Pilocarpine is typically administered at a dose of $5 \mathrm{mg}$ three times a day for at least 3 months and cevimeline is prescribed at a dose of $30 \mathrm{mg}$ three times a day for at least 3 months. ${ }^{46}$ Side effects include: excessive sweating, cutaneous vasodilatation, emesis, nausea, diarrhea, persistent hiccup, 
bronchoconstriction, hypotension, bradycardia, increased urinary frequency, and vision problems. Both pilocarpine and cevimeline are relatively contraindicated in patients with uncontrolled asthma or chronic pulmonary disease and in $\beta$-adrenergic blocker users, and should be used with caution in patients with active gastric ulcers or uncontrolled hypertension. Pilocarpine is also contraindicated in individuals with narrow-angle glaucoma and iritis, and should be used with caution in individuals with chronic pulmonary disease, asthma, or cardiovascular diseases. ${ }^{40}$

\section{Other sialogogues}

Anethole trithione is a cholagogue that has been shown to improve oral symptoms and increase the salivary flow in patients with xerostomia and hyposalivation. ${ }^{47}$ More studies are necessary to prove the efficacy of this medication. Patients who were treated with psychotropic drugs (tricyclic antidepressants or neuroleptics) and were suffering from xerostomia benefited from yohimbine use, an alpha 2 adrenoceptor antagonist. ${ }^{48}$

\section{Intraoral topical agents}

Intraoral topical agents are among the most common recommended treatments for the management of xerostomia. These include chewing gums, saliva stimulants, and substitutes. A topical sialogogue spray containing 1\% malic acid has recently shown its efficacy in managing symptoms of xerostomia in patients with antidepressant- or antihypertensive-induced dry mouth; ${ }^{49,50}$ however, this has the potential to cause mild enamel erosion. Commercially available sugar-free chewing gums and candies can also be used to simulate salivary flow. ${ }^{51}$ In particular, chewing gums have been shown to increase saliva secretion and decrease oral mucosal friction. ${ }^{52}$ In addition to chewing gum, saliva stimulants and substitutes (eg, gel, mouthwash, and toothpaste) provide over-the-counter alternatives for salivary gland hypofunction management. Other oral sprays, specifically oxygenated glycerol tri-ester, serve as an alternative treatment for dry mouth and have been proven to be more effective than other commercially available saliva substitutes. ${ }^{53}$ Saliva substitutes aim to increase viscosity and mimic natural saliva without altering the salivary flow. ${ }^{54}$ These agents contain minerals (eg, fluoride, calcium, and phosphate ions), carboxymethylcellulose or hydroxyethylcellulose, flavoring agents, and preservatives (eg, propyl or methyl paraben). ${ }^{38}$ Other efficacious remedies include mucoadhesive lipid-based bioerodible tablets ${ }^{55}$ or mucin spray, although their efficacy for management of xerostomia remains controversial. ${ }^{51,56-59}$ Mucin-containing lozenges provided benefit for the treatment of xerostomia when compared to a placebo. ${ }^{60}$ Other topical agents (toothpaste, mouth rinse, mouth spray, and gel) containing olive oil, betaine, and xylitol may be effective in improving xerostomia secondary to medication use. ${ }^{61}$ Of note, saliva substitute spray containing carboxymethylcellulose, ${ }^{62}$ xanthan gum-containing spray, ${ }^{63}$ or buffered Profylin gel ${ }^{64}$ did not seem to improve dry mouth symptoms. Also lemon lozenge use in individuals with xerostomia did not show any increase in salivary flow when compared to baseline paraffin-stimulated mean flow rate and the gum-stimulated flow rates. ${ }^{65}$ Of interest, Regelink et al reported that saliva substitutes are not effective in patients with reasonable stimulated salivary flow. ${ }^{66}$

The saliva substitute Saliva Orthana, a mucin-containing oral spray, was tested in a double-blind, singlephase, placebo-controlled trial for patients complaining of xerostomia. ${ }^{59}$ The results of this study did not show any significant improvement when compared to the placebo. When oral lubricants are considered, the gel formulation appears to be the most efficient and appreciated by patients. ${ }^{67}$ Patients taking oral lozenges of anhydrous crystalline maltose showed an increase in saliva production and a decrease in perceived symptoms of xerostomia. ${ }^{68}$ Patients applying the anticholinesterase physostigmine on the oral mucosa to stimulate salivary production from the minor glands reported great benefit, and this could be a valid alternative to systemic treatment. ${ }^{69}$

\section{Changes in medications}

Although the evidence available is limited, with patients on medications known to induce salivary gland hypofunction, a treatment alternative includes decreasing the dosage of the medications or potentially replacing the medications with less xerogenic drugs. ${ }^{70}$ Studies have shown that xerostomia became more manageable through medication dose reduction and medication replacement. ${ }^{71,72}$ Any change in medication should be discussed with the referring physician.

\section{Others}

Other remedies have been proposed for the management of xerostomia. Intraoral electrostimulation has also been tested to increase salivary flow. ${ }^{73,74}$ Furthermore, reports have shown that intraoral appliances, such as the saliva stimulation device Saliwell Crown or the electrostimulating device GenNarino, have been effective in reducing dry mouth and 
increasing the production of saliva. ${ }^{75}$ Acupuncture may be a useful adjunct for the stimulation of salivary flow in some patients with xerostomia and in patients with irradiationinduced xerostomia. However, additional larger studies are necessary to confirm these findings..$^{76,77}$

Finally, patients who undergo radiation of the head and neck region may benefit from the use of intensity-modified radiation therapy and/or of amifostine (cytoprotective agent). ${ }^{78}$

\section{Conclusion}

Xerostomia and hyposalivation remain a debilitating condition for many individuals. This review summarizes the diagnostic and therapeutic approaches to manage xerostomia and hyposalivation. Clinicians with a patient complaining of xerostomia have the opportunity to identify patients with true salivary gland hypofunction with effective diagnostic criteria and functional tests, and therefore prevent secondary effects. Although no standard treatment guidelines are available, many treatment options exist for the management of xerostomia and hyposalivation: topical agents to alleviate and/or prevent xerostomia, systemic therapy, or newer devices. While systemic agents such as pilocarpine or cevimeline have been largely studied, new medical devices require large well-designed clinical trials.

\section{Disclosure}

The authors report no conflicts of interest in this work.

\section{References}

1. Hopcraft MS, Tan C. Xerostomia: an update for clinicians. Aust Dent J 2010;55(3):238-244; quiz 353.

2. van der Putten GJ, Brand HS, Schols JM, de Baat C. The diagnostic suitability of a xerostomia questionnaire and the association between xerostomia, hyposalivation and medication use in a group of nursing home residents. Clin Oral Investig. 2011;15(2):185-192.

3. Fox PC, van der Ven PF, Sonies BC, Weiffenbach JM, Baum BJ. Xerostomia: evaluation of a symptom with increasing significance. J Am Dent Assoc. 1985;110(4):519-525.

4. Humphrey SP, Williamson RT. A review of saliva: normal composition, flow, and function. J Prosthet Dent. 2001;85(2):162-169.

5. Pedersen AM, Bardow A, Jensen SB, Nauntofte B. Saliva and gastrointestinal functions of taste, mastication, swallowing and digestion. Oral Dis. 2002;8(3):117-129.

6. Heintze U, Birkhed D, Björn H. Secretion rate and buffer effect of resting and stimulated whole saliva as a function of age and sex. Swed Dent J. 1983;7(6):227-238.

7. Sreebny LM, Vissink A, editors. Dry Mouth: the malevolent symptom. A clinical guide. Ames: Wiley-Blackwell; 2010.

8. Dawes C. How much saliva is enough for avoidance of xerostomia? Caries Res. 2004;38(3):236-240.

9. Cassolato SF, Turnbull RS. Xerostomia: clinical aspects and treatment. Gerodontology. 2003;20(2):64-77.

10. Villa A, Polimeni A, Strohmenger L, Cicciù D, Gherlone E, Abati S. Dental patients' self-reports of xerostomia and associated risk factors. J Am Dent Assoc. 2011;142(7):811-816.
11. Ekström J, Khosravani N, Castagnola M, Messana I. Saliva and the control of its secretion. In: Ekberg O, editor. Dysphagia: Diagnosis and Treatment. Berlin: Springer-Verlag; 2012:19-47.

12. Thomson WM. Issues in the epidemiological investigation of dry mouth. Gerodontology. 2005;22(2):65-76.

13. Bergdahl M, Bergdahl J. Low unstimulated salivary flow and subjective oral dryness: association with medication, anxiety, depression, and stress. J Dent Res. 2000;79(9):1652-1658.

14. Leal SC, Bittar J, Portugal A, Falcão DP, Faber J, Zanotta P. Medication in elderly people: its influence on salivary pattern, signs and symptoms of dry mouth. Gerodontology. 2010;27(2):129-133.

15. Astor FC, Hanft KL, Ciocon JO. Xerostomia: a prevalent condition in the elderly. Ear Nose Throat J. 1999;78(7):476-479.

16. Liu B, Dion MR, Jurasic MM, Gibson G, Jones JA. Xerostomia and salivary hypofunction in vulnerable elders: prevalence and etiology. Oral Surg Oral Med Oral Pathol Oral Radiol. 2012;114(1): 52-60.

17. Locker D. Subjective reports of oral dryness in an older adult population. Community Dent Oral Epidemiol. 1993;21(3):165-168.

18. Thorselius I, Emilson CG, Osterberg T. Salivary conditions and drug consumption in older age groups of elderly Swedish individuals. Gerodontics. 1988;4(2):66-70.

19. Nagler RM. Salivary glands and the aging process: mechanistic aspects, health-status and medicinal-efficacy monitoring. Biogerontology. 2004;5(4):223-233.

20. Valdez IH, Fox PC. Diagnosis and management of salivary dysfunction. Crit Rev Oral Biol Med. 1993;4(3-4):271-277.

21. Fox PC, Busch KA, Baum BJ. Subjective reports of xerostomia and objective measures of salivary gland performance. J Am Dent Assoc. 1987;115(4):581-584.

22. Thomson WM, Chalmers JM, Spencer AJ, Williams SM. The Xerostomia Inventory: a multi-item approach to measuring dry mouth. Community Dent Health. 1999;16(1):12-17.

23. Sreebny LM, Valdini A. Xerostomia. Part I: Relationship to other oral symptoms and salivary gland hypofunction. Oral Surg Oral Med Oral Pathol. 1988;66(4):451-458.

24. Eisbruch A, Rhodus N, Rosenthal D, et al. How should we measure and report radiotherapy-induced xerostomia? Semin Radiat Oncol. 2003;13(3):226-234.

25. Pai S, Ghezzi EM, Ship JA. Development of a Visual Analogue Scale questionnaire for subjective assessment of salivary dysfunction. Oral Surg Oral Med Oral Pathol Oral Radiol Endod. 2001;91(3): 311-316.

26. Singh ML, Papas A. Oral Implications of Polypharmacy in the Elderly. Dent Clin North Am. 2014;58(4):783-796.

27. Smidt D, Torpet LA, Nauntofte B, Heegaard KM, Pedersen AM. Associations between labial and whole salivary flow rates, systemic diseases and medications in a sample of older people. Community Dent Oral Epidemiol. 2010;38(5):422-435.

28. Osailan S, Pramanik R, Shirodaria S, Challacombe SJ, Proctor GB. Investigating the relationship between hyposalivation and mucosal wetness. Oral Dis. 2011;17(1):109-114.

29. Löfgren CD, Wickström C, Sonesson M, Lagunas PT, Christersson C. A systematic review of methods to diagnose oral dryness and salivary gland function. BMC Oral Health. 2012;12:29.

30. Navazesh M. Methods for collecting saliva. Ann N Y Acad Sci. 1993 694:72-77.

31. Chen A, Wai Y, Lee L, Lake S, Woo SB. Using the modified Schirmer test to measure mouth dryness: a preliminary study. J Am Dent Assoc. 2005;136(2):164-170; quiz 229-230.

32. Navazesh M, Kumar SK; University of Southern California School of Dentistry. Measuring salivary flow: challenges and opportunities. J Am Dent Assoc. 2008;139 Suppl:35S-40S.

33. Lashley KS. Reflex secretion of the human parotid gland. J Exp Psychol. 1916;1(6):461-493.

34. Schneyer LH. Method for the collection of separate submaxillary and sublingual salivas in man. J Dent Res. 1955;34(2):257-261. 
35. Wolff A, Begleiter A, Moskona D. A novel system of human submandibular/sublingual saliva collection. J Dent Res. 1997;76(11): $1782-1786$.

36. Eliasson L, Carlén A. An update on minor salivary gland secretions. Eur J Oral Sci. 2010;118(5):435-442.

37. Smidt D, Torpet LA, Nauntofte B, Heegaard KM, Pedersen AM. Associations between oral and ocular dryness, labial and whole salivary flow rates, systemic diseases and medications in a sample of older people. Community Dent Oral Epidemiol. 2011;39(3):276-288.

38. Visvanathan V, Nix P. Managing the patient presenting with xerostomia: a review. Int J Clin Pract. 2010;64(3):404-407.

39. Takakura AC, Moreira TS, Laitano SC, De Luca Júnior LA, Renzi A, Menani JV. Central muscarinic receptors signal pilocarpine-induced salivation. J Dent Res. 2003;82(12):993-997.

40. Wiseman LR, Faulds D. Oral pilocarpine: a review of its pharmacological properties and clinical potential in xerostomia. Drugs. 1995;49(1): $143-155$.

41. Iwabuchi Y, Masuhara T. Sialogogic activities of SNI-2011 compared with those of pilocarpine and McN-A-343 in rat salivary glands: identification of a potential therapeutic agent for treatment of Sjorgen's syndrome. Gen Pharmacol. 1994;25(1):123-129.

42. Iwabuchi Y, Katagiri M, Masuhara T. Salivary secretion and histopathological effects after single administration of the muscarinic agonist SNI-2011 in MRL/lpr mice. Arch Int Pharmacodyn Ther. 1994;328(3):315-325.

43. Weber J, Keating GM. Cevimeline. Drugs. 2008;68(12):1691-1698.

44. Chambers MS, Jones CU, Biel MA, et al. Open-label, long-term safety study of cevimeline in the treatment of postirradiation xerostomia. Int J Radiat Oncol Biol Phys. 2007;69(5):1369-1376.

45. Braga MA, Tarzia O, Bergamaschi CC, Santos FA, Andrade ED, Groppo FC. Comparison of the effects of pilocarpine and cevimeline on salivary flow. Int J Dent Hyg. 2009;7(2):126-130.

46. Aframian DJ, Helcer M, Livni D, Robinson SD, Markitziu A, Nadler C. Pilocarpine treatment in a mixed cohort of xerostomic patients. Oral Dis. 2007;13(1):88-92.

47. Hamada T, Nakane T, Kimura T, et al. Treatment of xerostomia with the bile secretion-stimulating drug anethole trithione: a clinical trial. Am J Med Sci. 1999;318(3):146-151.

48. Bagheri H, Schmitt L, Berlan M, Montastruc JL. A comparative study of the effects of yohimbine and anetholtrithione on salivary secretion in depressed patients treated with psychotropic drugs. Eur J Clin Pharmacol. 1997;52(5):339-342.

49. Gómez-Moreno G, Guardia J, Aguilar-Salvatierra A, Cabrera-Ayala M, Maté-Sánchez de-Val JE, Calvo-Guirado JL. Effectiveness of malic acid $1 \%$ in patients with xerostomia induced by antihypertensive drugs. Med Oral Patol Oral Cir Bucal. 2013;18(1):e49-e55.

50. Gómez-Moreno G, Aguilar-Salvatierra A, Guardia J, et al. The efficacy of a topical sialogogue spray containing $1 \%$ malic acid in patients with antidepressant-induced dry mouth: a double-blind, randomized clinical trial. Depress Anxiety. 2013;30(2):137-142.

51. Furness S, Worthington HV, Bryan G, Birchenough S, McMillan R. Interventions for the management of dry mouth: topical therapies. Cochrane Database Syst Rev. 2011(12):CD008934.

52. Olsson H, Spak CJ, Axéll T. The effect of a chewing gum on salivary secretion, oral mucosal friction, and the feeling of dry mouth in xerostomic patients. Acta Odontol Scand. 1991;49(5):273-279.

53. Mouly SJ, Orler JB, Tillet Y, et al. Efficacy of a new oral lubricant solution in the management of psychotropic drug-induced xerostomia: a randomized controlled trial. J Clin Psychopharmacol. 2007;27(5): 437-443.

54. van der Reijden WA, Vissink A, Veerman EC, Amerongen AV. Treatment of oral dryness related complaints (xerostomia) in Sjögren's syndrome. Ann Rheum Dis. 1999;58(8):465-474.

55. Aframian DJ, Mizrahi B, Granot I, Domb AJ. Evaluation of a mucoadhesive lipid-based bioerodable tablet compared with Biotène mouthwash for dry mouth relief - a pilot study. Quintessence Int. 2010;41(3):e36-e42.
56. Blixt-Johansen G, Ek AC, Ganowiak W, et al. Improvement of oral mucosa with mucin containing artificial saliva in geriatric patients. Arch Gerontol Geriatr. 1992;14(2):193-201.

57. Duxbury AJ, Thakker NS, Wastell DG. A double-blind cross-over trial of a mucin-containing artificial saliva. Br Dent J. 1989;166(4):115-120.

58. van der Reijden WA, van der Kwaak H, Vissink A, Veerman EC, Amerongen AV. Treatment of xerostomia with polymer-based saliva substitutes in patients with Sjögren's syndrome. Arthritis Rheum. 1996;39(1): $57-63$.

59. Sweeney MP, Bagg J, Baxter WP, Aitchison TC. Clinical trial of a mucin-containing oral spray for treatment of xerostomia in hospice patients. Palliat Med. 1997;11(3):225-232.

60. Gravenmade EJ, Vissink A. Mucin-containing lozenges in the treatment of intraoral problems associated with Sjögren's syndrome. A doubleblind crossover study in 42 patients. Oral Surg Oral Med Oral Pathol. 1993;75(4):466-471.

61. Ship JA, McCutcheon JA, Spivakovsky S, Kerr AR. Safety and effectiveness of topical dry mouth products containing olive oil, betaine, and xylitol in reducing xerostomia for polypharmacy-induced dry mouth. J Oral Rehabil. 2007;34(10):724-732.

62. Donatsky O, Johnsen T, Holmstrup P, Bertram U. Effect of Saliment on parotid salivary gland secretion and on xerostomia caused by Sjögren's syndrome. Scand J Dent Res. 1982;90(2):157-162.

63. Jellema AP, Langendijk H, Bergenhenegouwen L, et al. The efficacy of Xialine in patients with xerostomia resulting from radiotherapy for head and neck cancer: a pilot-study. Radiother Oncol. 2001;59(2):157-160.

64. Persson A, Lingström P, Bergdahl M, Claesson R, van Dijken JW. Buffering effect of a prophylactic gel on dental plaque in institutionalised elderly. Gerodontology. 2007;24(2):98-104.

65. Stewart CM, Jones AC, Bates RE, Sandow P, Pink F, Stillwell J. Comparison between saliva stimulants and a saliva substitute in patients with xerostomia and hyposalivation. Spec Care Dentist. 1998;18(4):142-148.

66. Regelink G, Vissink A, Reintsema H, Nauta JM. Efficacy of a synthetic polymer saliva substitute in reducing oral complaints of patients suffering from irradiation-induced xerostomia. Quintessence Int. 1998;29(6):383-388

67. Furumoto EK, Barker GJ, Carter-Hanson C, Barker BF. Subjective and clinical evaluation of oral lubricants in xerostomic patients. Spec Care Dentist. 1998;18(3):113-118.

68. Fox PC, Cummins MJ, Cummins JM. Use of orally administered anhydrous crystalline maltose for relief of dry mouth. J Altern Complement Med. 2001;7(1):33-43.

69. Khosravani N, Birkhed D, Ekström J. The cholinesterase inhibitor physostigmine for the local treatment of dry mouth: a randomized study. Eur J Oral Sci. 2009;117:209-217.

70. Sreebny LM, Valdini A. Xerostomia. A neglected symptom. Arch Intern Med. 1987;147(7):1333-1337.

71. Azodo CC, Ezeja EB, Omoaregba JO, James BO. Oral health of psychiatric patients: the nurse's perspective. Int J Dent Hyg. 2012;10(4):245-249.

72. Trindade E, Menon D, Topfer LA, Coloma C. Adverse effects associated with selective serotonin reuptake inhibitors and tricyclic antidepressants: a meta-analysis. CMAJ. 1998;159(10):1245-1252.

73. Strietzel FP, Lafaurie GI, Mendoza GR, et al. Efficacy and safety of an intraoral electrostimulation device for xerostomia relief: a multicenter, randomized trial. Arthritis Rheum. 2011;63(1):180-190.

74. Strietzel FP, Martin-Granizo R, Fedele S, et al. Electrostimulating device in the management of xerostomia. Oral Dis. 2007;13(2):206-213.

75. Alajbeg I, Falcão DP, Tran SD, et al. Intraoral electrostimulator for xerostomia relief: a long-term, multicenter, open-label, uncontrolled, clinical trial. Oral Surg Oral Med Oral Pathol Oral Radiol. 2012;113(6):773-781.

76. Blom M, Dawidson I, Angmar-Månsson B. The effect of acupuncture on salivary flow rates in patients with xerostomia. Oral Surg Oral Med Oral Pathol. 1992;73(3):293-298. 
77. O'Sullivan EM, Higginson IJ. Clinical effectiveness and safety of acupuncture in the treatment of irradiation-induced xerostomia in patients with head and neck cancer: a systematic review. Acupunct Med. 2010;28(4):191-199.
78. Gu J, Zhu S, Li X, Wu H, Li Y, Hua F. Effect of amifostine in head and neck cancer patients treated with radiotherapy: a systematic review and meta-analysis based on randomized controlled trials. PLoS One. 2014;9(5):e95968.

\section{Publish your work in this journal}

Therapeutics and Clinical Risk Management is an international, peerreviewed journal of clinical therapeutics and risk management, focusing on concise rapid reporting of clinical studies in all therapeutic areas outcomes, safety, and programs for the effective, safe, and sustained use of medicines. This journal is indexed on PubMed Central, CAS
EMBase, Scopus and the Elsevier Bibliographic databases. The manuscript management system is completely online and includes a very quick and fair peer-review system, which is all easy to use. Visit http://www.dovepress.com/testimonials.php to read real quotes from published authors.

Submit your manuscript here: http://www.dovepress.com/therapeutics-and-clinical-risk-management-journal 